\title{
ISTVÁN MÉSZÁROS E A INTERPRETAÇÃO DE MARX: O LUGAR E A FORÇA DA RADICALIZAÇÃO DA CRÍTICA IMANENTE
}

\author{
Jesus Ranieri ${ }^{1}$
}

\begin{abstract}
RESUMO
O presente texto tem a intenção de apontar que a produção de István Mészaros representa uma forte interpretação da teoria de Marx, especialmente a chamada Crítica da Economia Política, do ponto de vista de sua radicalização. O diagnóstico de Mészáros é aquele de que a relação social de produção denominada capital atinge todas as esferas da vida e de que sua crise de realização é igualmente abrangente, revelando-se como crise financeira, humanitária, das ideologias e também da cultura.
\end{abstract}

\begin{abstract}
This paper intends to point out that the production of István Mészáros is a strong interpretation of Marx's theory, especially the Critique of Political Economy, from the point of view of its radicalization. The diagnosis of Mészáros is that of the social relation called capital output reaches all walks of life and their realization crisis is equally comprehensive, revealing itself as a financial crisis, humanitarian, ideologies and also culture.
\end{abstract}

O texto que ora redijo será um relato breve, pois há quem conheça a produção de István Mészáros muito melhor do que eu. Mas não pode ser franqueada a qualquer estudioso do pensamento de Marx ignorância acerca da produção teórica do professor Mészáros, pois sem ele Marx seria certamente um autor menos completo - e não porque os escritos deste último sejam datados, mas justamente porque são radicalmente atuais e essa atualidade é traduzida e comprovada por aquilo que Mészáros tem escrito nas últimas décadas. Já faz tempo considerável que o autor húngaro ocupa um lugar central na bibliografia que trata de temas oriundos das preocupações de Marx e, ainda mais, ocupa lugar central no que diz respeito à originalidade dispensada à intensificação e comprovação destes mesmos temas. Porém, a plêiade que caracteriza a produção de Mészáros é tão ampla que se torna muito difícil não distinguí-lo daqueles intelectuais que pertencem à mesma geração e que, por mais eruditos que sejam, não conseguem comungar da mesma competência crítica, principalmente no que diz respeito à reconstrução do pensamento e da situação social que lhes são objeto.

\footnotetext{
1 Sociólogo. Professor do Departamento de Sociologia do Instituto de Filosofia e Ciências Humanas da Universidade Estadual de Campinas (IFCH-Unicamp). E-mail: jranieri@uol.com.br
} 
Para além disso, ainda mais, a importância de Mészáros não está restrita à interpretação professoral das teses de Marx - o significado maior de sua obra talvez esteja mesmo na contribuição dada à reinterpretação daquilo que Marx chamou de capital (e não somente o exposto em $O$ capital), incluindo aí resultados que certamente nem o próprio Marx vislumbrava, o que confere à obra de István Mészáros uma intensa e profícua originalidade. Ainda que a sedimentação da carreira deste autor tenha se iniciado há mais de quatro décadas, sem dúvida o cuidado com a universalidade das determinações já antecipadas por Marx constitui a parte significativa daquilo que foi, durante esse período, o objeto das pesquisas do pensador húngaro - e da condição histórica de realização e consolidação do fenômeno da alienação até a investigação mais profunda da relação social de produção da qual ela deriva na sociedade moderna, o percurso da obra de István Mészáros consegue juntar num desdobramento universal e ao mesmo tempo genético a totalidade do imbricamento econômico do qual somos objeto, ainda que também sujeitos sem controle racional da própria ação. É por isso que a tríade representada pela troca-divisão do trabalho-propriedade privada ${ }^{2}$ seja talvez a primeira expressão do conjunto daquilo que István Mészáros nos mostraria como futuro de uma subordinação histórica, ou seja, ao estudar o conteúdo do fenômeno alienação em Marx, já estava no horizonte a apresentação da qualidade absolutamente nova do sistema do capital como definidor de uma situação jamais encontrada antes, aquela cuja especificidade se ambientava na potencialidade de cingir universalmente o conjunto das faculdades identitárias de épocas e gerações, a partir do diagnóstico de uma realidade perigosa e multifacetada:

"A alienação da humanidade, no sentido fundamental do termo, significa perda de controle: sua corporificação numa força externa que confronta os indivíduos como um poder hostil e potencialmente destrutivo. Quando Marx analisou a alienação nos seus Manuscritos de 1844, indicou os seus quatro principais aspectos: 1) a alienação dos seres humanos em relação à natureza; 2) à sua própria atividade produtiva; 3) à sua espécie, como espécie humana; e 4) de uns em relação aos outros. Ele afirmou enfaticamente que tudo isso não é uma "fatalidade da natureza" - como de fato são representados os antagonismos estruturais do capital, a fim de deixá-los onde estão - mas uma forma de auto-alienação. Dito de outra forma, não é o feito de uma força externa todo-poderosa, natural ou metafísica, mas o resultado de um tipo determinado de desenvolvimento histórico que pode ser positivamente alterado pela intervenção consciente no processo histórico para 'transcender a auto-alienação do trabalho'.

\footnotetext{
${ }^{2}$ Cf. Mészáros, I. A teoria da alienação em Marx. São Paulo: Boitempo editorial, 2006, passim.
}

\begin{tabular}{|l|l|l|l|l|}
\hline Gevista Dialectus & Ano 2 & n.7 & Setembro-Dezembro 2015 & p. 5-12 \\
\hline
\end{tabular}


$\mathrm{Na}$ fase ascensional do desenvolvimento do sistema, o controle do metabolismo social pelo capital resultou num antes inimaginável aumento das forças de produção. Mas o outro lado de todo esse aumento das forças de produção é a perigosa multiplicação das forças de destruição, a menos que prevaleça um controle consciente de todo o processo a serviço de um projeto humano positivo. O problema é que o capital é incompatível com um modo alternativo de controle, não importando o quanto sejam devastadoras as consequências da imposição de seu próprio projeto fetichista de expansão incontrolável do capital"3.

O problema todo está aí. Mészáros construiu o texto acima em 2004, como parte do prefácio à quinta edição inglesa de seu livro sobre o conceito de alienação em Marx, este mesmo trabalho que ora serve como uma das bases para o desenvolvimento de nosso argumento. Mas a leitura atenta da letra original só corrobora a impressão passada por Mészáros do poder intrínseco do capital sobre as nossas vidas, defesa de argumento já presente lá no final da década de 60 do século passado. Tanto lá quanto aqui, o que prevalece é a crença de que o sistema do capital não se restringe à sua composição orgânica e nem à sua reprodução técnica e essa certeza seguramente é a pedra de toque daquilo que herdamos da percepção do autor - a afirmação de que, por ser sociometabólico, o sistema do capital engendra e condiciona a plurivocidade dos elementos que ele determina, nos planos abstrato e concreto do conjunto da produção e reprodução da vida humana.

“Antes de mais nada, é necessário insistir que o capital não é simplesmente uma 'entidade material' - também não é (...) um 'mecanismo' racionalmente controlável, como querem fazer crer os apologistas do supostamente neutro 'mecanismo de mercado' (a ser alegremente abraçado pelo 'socialismo de mercado') - mas é, em última análise, uma forma incontrolável de controle sociometabólico. A razão principal por que este sistema forçosamente escapa a um significativo grau de controle humano é precisamente o fato de ter, ele próprio, surgido no curso da história como uma poderosa - na verdade, até o presente, de longe a mais poderosa - estrutura 'totalizadora' de controle à qual tudo o mais, inclusive seres humanos, deve se ajustar, e assim provar sua 'viabilidade produtiva', ou perecer, caso não consiga se adaptar. Não se pode imaginar um sistema de controle mais inexoravelmente absorvente - e, neste importante sentido, 'totalitário' - do que o sistema do capital globalmente dominante, que sujeita cegamente aos mesmos imperativos a questão da saúde e a do comércio, a educação e a agricultura, a arte e a indústria manufatureira, que implacavelmente sobrepõe a tudo seus próprios critérios de viabilidade, desde as menores unidades de seu 'microcosmo' até as mais gigantescas empresas transnacionais, desde as mais íntimas relações pessoais aos mais complexos processos de tomada de decisão dos vastos monopólios industriais, sempre a favor dos fortes e contra os fracos. No entanto, é irônico (e bastante absurdo) que os propagandistas de tal sistema

${ }^{3}$ Idem, ibidem, p.14, itálicos do autor.

\begin{tabular}{|l|l|l|l|l|}
\hline Q ovista Dialectus & Ano 2 & n.7 & Setembro-Dezembro 2015 & p. 5-12 \\
\hline
\end{tabular}


acreditem que ele seja inerentemente democrático e suponham que ele realmente seja a base paradigmática de qualquer democracia concebível"4.

Essa percepção não é diferente daquela de Marx. Pelo contrário, a atualiza e aprofunda, refletindo em alto grau as conclusões dele a respeito da insidiosa penetração da forma de ser do capital no conjunto do ser social. A teoria marxiana compreendia o capital como sendo um processo social total, ancorado na expropriação generalizada da força humana de trabalho, expropriação que qualifica uma nova forma de sociedade, particularizando-a justamente pelo efeito brutal desta expropriação universal. Só que o texto de Marx penetra mais profundamente na própria articulação interna e ontológica da formação do capital, examinando o passo a passo de cada elemento constituinte desta formação e a maneira segundo a qual estes componentes alimentam a trajetória e composição de algo maior, exposição ancorada em categorias que preenchem de conteúdo novo a própria identidade do referido vir-a-ser - uma exposição propositadamente preocupada com gênese e desenvolvimento. Mercadoria, trabalho, trabalho concreto, trabalho abstrato, valor, forma do valor, valor de uso, valor de troca, força de trabalho, dinheiro: estes componentes conduzem o leitor ao habitáculo fechado da noção própria de capital, em que a contradição não é esfera exterior a dar sentido lógico à unidade, mas o verdadeiro elo e força a partir da qual estes componentes se combinam e formam o novo tecido da produção e reprodução social.

Este percurso genético aparece bem menos em Mészáros, justamente porque o autor húngaro examina a fase atual e mais nefasta daquela constituição. Também neste caso, tratase de uma investigação que tem por objetivo acompanhar a forma segundo a qual a exposição da crítica da economia política obedece em larga medida àquela proposta que preconiza que o conhecimento se torna possível a partir da apresentação do objeto enquanto forma de manifestação da verdade, ou seja, compreender o objeto a partir dos condicionamentos que o compõem, assim como o processo que alimenta o desenvolvimento interior dessa composição. A força da contribuição de Mészáros está na atualização desse informe, no seu mergulho científico nas entranhas de um sistema cuja debilidade projeta sua autoconstituição como crise permanente e, portanto, como entrave econômico e político ao concurso da continuidade da vida humana assim como está hoje constituída. Em outras palavras, a crítica do capital a partir de sua contradição interna, especialmente sob o lugar e a determinação do trabalho, corrobora

\footnotetext{
${ }^{4}$ Mészáros, I. Para além do capital: rumo a uma teoria da transição. São Paulo: Boitempo editorial, 2002, p. 96, itálicos do autor.
}

\begin{tabular}{|l|l|l|l|l|}
\hline Renita & Ano 2 & n.7 & Setembro-Dezembro 2015 & p. 5 - 12 \\
\hline
\end{tabular}


a apreensão de que o modo de produção capitalista tem sua originalidade em dois fundamentos: em primeiro lugar, o capital como processo social total, que subsume e torna constitutivo de si a totalidade do ambiente social, ancorado ainda hoje e insistentemente na produção universal do valor. Em segundo lugar, a percepção de que semelhante originalidade só podia ter sua gênese e desenvolvimento a partir da expropriação universal tanto da base material quanto subjetiva da reprodução humana, colocando no lugar de representações autônomas as representações oriundas da nova universalidade do capital enquanto processo social de produção.

Nesse sentido e curiosamente, a cronologia da obra de Mészáros coincide inteiramente com a própria cronologia das conclusões de Marx a respeito da amplitude do fenômeno da alienação e, já na maturidade de ambos, do quanto esse fenômeno deve sua forma de ser interior à realidade de afirmação histórica do próprio capital, ainda que Marx não tenha jamais se preocupado em afirmar nas obras de maturidade a qualidade do modo de ser específico da alienação, mesmo que o referido fenômeno esteja intensamente presente nas linhas de $O$ capital como parte componente e constitutiva do movimento do capital em geral. Indo mais longe: em termos metodológicos, e considerando a herança hegeliana de Marx, poderíamos dizer que a originalidade de Mészáros está presente, em primeiro lugar, na percepção de que a estrutura última do pensamento marxiano não somente reteve o aprendizado oriundo da filosofia clássica alemã, especialmente Hegel, mas que, em segundo lugar, só vê sentido científico nesta última a partir de sua interpretação e revelação pelo materialismo - passo já dado em larga medida por Lukács, mas não a ponto de interpor com tanta competência o alcance do sistema do capital. E é justamente na reconstituição do conjunto do movimento que a composição do capital está presente, precisamente na demonstração de que ele, o capital, não existe sem o trabalho e, mais, que o único elemento ineliminável é este último, posto que não há ser humano sem produção de elementos vitais e sem representações aqueles e estas componentes que são do trabalho como um assento material, ao mesmo tempo genético e reflexivo.

O problema, porém, é que a intensidade dos escritos de Mészáros nem sempre nos deixa entrever esses componentes marcadamente filosóficos, embora o conjunto daquilo que escreveu seja profundamente voltado para a relação pensamento-matéria: é justamente por causa da radicalidade do texto que a filosofia surge, ou seja, o pensamento eivado de força material não deixa brecha para ser interpretado como potência puramente abstrata ou ainda

\begin{tabular}{|l|l|l|l|l|}
\hline Govista Dialactus & Ano 2 & n.7 & Setembro-Dezembro 2015 & p. 5-12 \\
\hline
\end{tabular}


autônoma, retendo-se em fragilidade ou inocência. Ao citar História e consciência de classe, por exemplo, livro poderosíssimo do ponto de vista do leque de influências e das ressonâncias nos meios operário e intelectual e que não pode ser alcunhado como um texto 'de direita', é dito sem rodeios que há ali um momento de "subordinação voluntarista de Lukács" quando este último vê a superação da luta de classes a partir da superação de "meros expedientes econômicos" e que, por causa disso, a "ênfase irrealista e exagerada colocada nos fatores ideológicos e políticos acompanha passo a passo a fatal subestimação do poder de recuperação do capital e da continuidade do seu domínio"5. Nem Lukács escapa da interpretação levada a efeito por Mészáros de que a amplitude da dominação do capital leva à sua apologia num tom invertido, mesmo pelos mais céleres pensadores.

O voluntarista reducionismo invertido implícito (...) tem sido uma das principais razões da legendária influência de História e consciência de classe não apenas sobre o marxismo de esquerda dos anos 20 e 30, mas também sobre a 'teoria crítica' - tanto na época de sua criação como nos anos do pós-guerra - e ainda, depois, sobre o movimento estudantil nos anos 60, especialmente na Alemanha. Publicado em um momento em que o capital estava bem adiantado para assegurar em novas bases a sua estabilidade, quando a onda revolucionária do final da guerra havia se exaurido, História e consciência de classe, de modo apaixonado, recusou-se a aceitar a situação que surgia e apelou diretamente ao ideal da consciência totalizante como sua única aliada contra as graves desvantagens da nova estabilidade. Portanto, não constitui surpresa que continue a encontrar ecos favoráveis em movimentos intelectuais socialmente muito isolados, ainda que desafiadores, os quais tentam articular, em circunstâncias similares de imobilidade social - contra o pano de fundo da aparente integração da classe trabalhadora e suas organizações tradicionais - a ideia de uma rebelião consciente contra o poder da reificação" .

Vê-se que o crédito na relação ineliminável entre condições materiais de produção e pensamento é levado em Mészáros ao seu extremo, no íntimo sentido de que é uma relação inesgotável, mas bastante difícil de analisar do ponto de vista da justa troca de determinações. No caso do autor húngaro não há dúvida que a intensidade do condicionamento material é e será sempre o motor do conteúdo da reflexão, seja em qual sentido for; seja em que sentido político ou econômico for. Na interpretação de Mészáros, o radicalismo de qualquer posição socialista só é possível na medida em que a percepção deste movimento tenha sentido universal enquanto movimento de massa, global, sem deixar de lado na leitura da realidade as

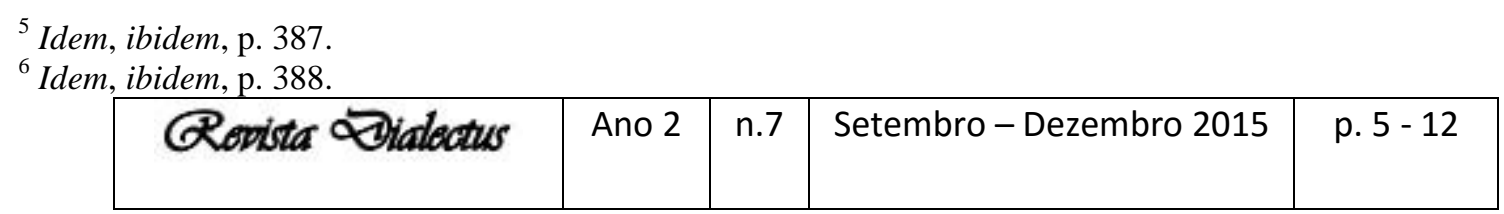


potencialidades de reação do próprio capital, que sempre são muito fortes e eficazes, inclusive do ponto de vista de sua presença na capitulação ideológica de grupos de esquerda. Novamente a oposição entre capital e trabalho se erige no sentido da determinação do pensamento e, no caso específico da Rússia - lugar histórico de realização de uma revolução que pagou e paga o elevado preço da reação do sistema do capital como um todo, mas que não fugiu jamais à lógica de extração do trabalho excedente por via política - a tensão com a legalidade parlamentar do ocidente em larga medida marcou o movimento interno de rompimento com a estrutura social que antecede o processo revolucionário e se mantém após a eclosão da revolução, num conflito contínuo.

A ideologia apenas não poderia superar a clivagem que objetivamente separava esses movimentos nos termos dos diferentes graus de desenvolvimento dos seus países; do seu tipo de desenvolvimento relativamente privilegiado ou dependente; da posição mais ou menos favorável de que os países em questão ocupavam no sistema global das hierarquias imperialistas; do caráter dos respectivos Estados tal como desenvolvidos por um longo período histórico; e das estruturas organizacionais viáveis da transformação socioeconômica e político-cultural que poderia ser visada no interior da base material estabelecida (ou herdada) e sua complexa superestrutura em cada país particular. É por isso que as observações de Lenin, na sequência da Revolução Russa, descrevendo esta última como modelo e 'futuro inevitável e próximo' dos países ocidentais de capitalismo mais avançado, teriam que se revelar desesperadamente otimistas, ao passo que as palavras de Rosa Luxemburgo - 'Na Rússia, o problema poderia apenas ser posto, mas não poderia ser solucionado na Rússia' - resistiriam ao teste do tempo"7.

É óbvio que estes elementos elencados acima e tão rapidamente expostos - alienação, capital, ideologia e socialismo real - não foram nem de perto considerados de um ponto de vista a situá-los como componentes de uma teoria que nos dias de hoje seria a referência para a saída econômica e política da crise de civilização que estamos vivendo - e Mészáros nos ajuda a entendê-la porque envolve nela o papel do Estado, assim como sua teoria da transição também o contempla. E quanto àqueles quatro elementos e depois este último, um dos poucos autores a enfrentar a questão de um ponto de vista também teórico é, sem dúvida, o próprio Mészáros, uma vez que o conjunto daquilo que é essa sua produção teórica preconizará sempre a passagem de uma sociedade baseada no sistema do capital para uma sociedade edificada sobre o trabalho humano concreto. Aliás, para ele, esta é a única saída, sob pena de

\footnotetext{
${ }^{7}$ Idem, ibidem, 389-390, itálicos do autor.
}

\begin{tabular}{|c|c|c|c|c|}
\hline Q & Ano 2 & n.7 & Setembro-Dezembro 2015 & p. 5-12 \\
\hline
\end{tabular}


não termos, num futuro relativamente próximo, saída alguma, e isso por causa da tenacidade do próprio capital em reproduzir-se a partir dos componentes que ele mesmo avilta e suprime.

E é bastante claro que essa percepção do capital com potencialidade para suprimir a vida humana tem a ver com a unidade entre decisão política e poderio econômico, ou seja, a força de ação do imperialismo na ácida investida pela realização e reprodução do valor econômico. A reprodução nos dias de hoje da política de colonização, que atua tanto na divisão internacional do trabalho quanto nas ocupações territoriais está levando o planeta para um beco sem saída, situação para a qual não será mais suficiente o puro e simples uso da força, na medida em que a crise se estrutura cada vez mais como movimento endógeno e, pior, ocupando maiores espaços do globo. Mais do que nunca a máxima se expõe mesmo como a alternativa entre 'socialismo ou barbárie', estando a segunda, infelizmente, sensivelmente à frente do primeiro.

\section{REFERÊNCIAS}

CLARK, Brett \& BELLAMY FOSTER, John. A dialética do metabolismo social e ecológico: Marx, Mészáros e os limites absolutos do capital. In JINKINGS, Ivana \& NOBILE, Rodrigo (orgs.). István Mészáros e os desafios do tempo histórico. São Paulo: Boitempo editorial, 2011.

MÉSZÁROS, István. A teoria da alienação em Marx. São Paulo: Boitempo editorial, 2006.

Para além do capital: rumo a uma teoria da transição. São Paulo: Boitempo editorial, 2002.

\begin{tabular}{|l|l|l|l|l|}
\hline Govista Dialactus & Ano 2 & n.7 & Setembro-Dezembro 2015 & p. 5-12 \\
\hline
\end{tabular}

